\title{
Los turismos de interior: un enfoque desde la dimensión de las modalidades turístico-recreativas
}

\author{
Daniel Díez Santo
}

Universidad de Alicante. Instituto Universitario de Investigaciones Turísticas

daniel.diez@ua.es

Recepción: diciembre de 2010

Aceptación: enero de 2012

\section{Resumen}

El turismo de interior representa un marco de trabajo ideal para el análisis de la actividad turística desde la perspectiva geográfica. Este concepto sustituye la habitual componente productiva por una visión integradora y transversal que encuentra su fundamento en el territorio. El turismo de interior no es en sí mismo un producto turístico, sino la suma de numerosas modalidades y fórmulas turístico-recreativas. De este modo, coexisten productos tradicionales ligados al medio rural y natural con otros productos turísticos extrapolados de manera forzada desde la franja litoral e incluso nuevos productos emergentes que están introduciéndose paulatinamente en el mundo rural.

En este artículo, se pretende llevar a cabo una aproximación teórico-conceptual a la amalgama de modalidades y fórmulas turístico-recreativas que tendrán que aprender a convivir en los espacios turísticos de interior. La competitividad del turismo de interior dependerá en buena medida del conocimiento de cada modalidad y del grado de ajuste alcanzado entre los diferentes productos turísticos presentes en un mismo territorio.

Palabras clave: turismo de interior; producto turístico; aproximación teórico-conceptual; compatibilidad productiva; perspectiva geográfica.

Resum. Els turismes d'interior: un enfocament des de la dimensió de les modalitats turisticorecreatives

El turisme d'interior representa un marc de treball ideal per analitzar l'activitat turística des de la perspectiva geogràfica. Este concepte substituïx l'habitual component productiu per una visió integradora i transversal que troba el seu fonament en el territori. El turisme d'interior no és en si mateix un producte turístic, sinó la suma de nombroses modalitats i fórmules turisticorecreatives. D'esta manera, coexistixen productes tradicionals lligats al medi rural i natural amb altres productes turístics extrapolats de manera forçada des de la franja litoral, i inclús, nous productes emergents que s'estan introduint gradualment en el món rural. 
En aquest article, s'hi pretén dur a terme una aproximació teoricoconceptual a l'amalgama de modalitats i fórmules turisticorecreatives que hauran d'aprendre a conviure en els espais turístics d'interior. La competitivitat del turisme d'interior dependrà en gran manera del coneixement de cada modalitat i del grau d'ajust aconseguit entre els diferents productes turístics presents en un mateix territori.

Paraules clau: turisme d'interior; producte turístic; aproximació teoricoconceptual; compatibilitat productiva; perspectiva geogràfica.

Résumé. Tourisme intérieur: un point de vue depuis la dimension des modalités touristiquesrécréatives

Le tourisme intérieur représente un cadre de travail idéal pour l'analyse de l'activité touristique depuis la perspective géographique. Ce concept substitue l'habituel composant productif par une vision intégratrice et transversale qui trouve son fondement dans le territoire. Le tourisme intérieur n'est pas en lui-même un produit touristique, mais l'ensemble de nombreuses modalités et différentes formules touristiques-récréatives. Ainsi, les produits traditionnels liés au milieu rural et naturel coexistent avec d'autres produits touristiques extrapolés d'une manière forcée depuis la frange littorale, en plus d'autres nouveaux produits émergents qui s'introduisent petit à petit au monde rural.

Cet article essaie de mener une approche théorique-conceptuelle à l'amalgame de modalités et de formules touristiques-récréatives qui devront apprendre à vivre ensemble dans les espaces touristiques d'intérieur. La compétitivité du tourisme intérieur dépendra en grande partie de la connaissance de chaque modalité et du degré d'ajustement atteint entre différents produits touristiques présents dans le même territoire.

Mots clé: tourisme intérieur; produit touristique; approche théorique-conceptuelle; compatibilité productive; perspective géographique.

Abstract. Inland tourism: An approach from the dimension of tourist-recreational modalities

Inland tourism represents an ideal framework for the analysis of tourist activity from a geographical perspective. This concept replaces the usual productive component with an integrating, cross-sectional approach that has its foundations in the territory. Inland tourism is not a tourist product in itself but the sum of numerous tourist-recreational modalities and formulas. Consequently, traditional products related with rural and natural contexts coexist with other tourist products imported in a forced way from coastal areas and even with new emergent products which are progressively entering rural areas.

The aim of this article is to adopt a theoretical-conceptual approach to the mixture of tourist-recreational modalities and formulas that must learn to coexist within inland tourism spaces. The competitiveness of inland tourism will largely depend on the actors' knowledge of each modality and the degree of adaptation between different tourist products which are found in the same territory.

Keywords: inland tourism; tourist product; theoretical-conceptual approach; productive compatibility; geographic perspective. 


\section{Sumario}

1. El turismo de interior: una amalgama de modalidades y fórmulas turístico-recreativas

2. Productos tradicionales ligados al medio rural y natural

3. Productos emergentes o en proceso de consolidación
4. Productos importados del medio litoral o urbano

5. Discusión y conclusiones

Bibliografía

La presente investigación ${ }^{1}$ pretende explorar la base teórica que sustenta el turismo de interior desde una perspectiva integradora que recoja las aportaciones científicas relativas a las diferentes modalidades y fórmulas turísticorecreativas que tienen cabida dentro de este concepto "paraguas» con marcado carácter geográfico.

Una vez analizados los «turismos de interior» desde el plano teórico, el objetivo de la investigación se centra en la identificación empírica del grado de ajuste de los diferentes productos turísticos con aquellos elementos o aspectos que resultan cruciales para el buen funcionamiento de la actividad turística en espacios interiores (medio ambiente, otros sectores de actividad económica, sociedad local, diferentes segmentos de demanda turística, complementariedad territorial y productiva, posibilidad innovadora y capacidad competitiva). Para este cometido, el apartado de conclusiones recoge una matriz de compatibilidad productiva, que refleja y valora de forma sintetizada la relación entre productos y elementos de interacción preferentes para los espacios turísticos de interior.

\section{El turismo de interior: una amalgama de modalidades y fórmulas turístico-recreativas}

El turismo de interior responde a un concepto muy amplio donde tiene cabida lo rural, pero también lo natural y lo urbano. En este sentido, Valenzuela (1997) insistía en la gran heterogeneidad que presentaban los turismos de interior, en cuanto formaban parte de nuevas modalidades no ligadas física ni perceptualmente a los espacios litorales ni a sus manifestaciones ambientales, urbanísticas y económicas. Así, por turismo de interior se entendía todo turismo que se dirigía a poblaciones no costeras. Sin embargo, con el paso del tiempo, esto está cambiando y cada vez son más frecuentes las dinámicas de complementariedad territorial entre los espacios litorales e interiores en favor de una creciente movilización de flujos turísticos. Esta nueva situación está provocando la convivencia de productos tradicionales ligados al medio rural y

1. La investigación presentada en este artículo forma parte de la tesis doctoral titulada La planificación estratégica de los espacios turisticos interiores: Una propuesta metodológica aplicada en el interior de Alicante, que fue defendida en el año 2010 en el seno del programa de doctorado «Planificación y gestión sostenible de destinos turísticos», del Instituto Universitario de Investigaciones Turísticas de la Universidad de Alicante. 
natural (turismo de retorno, turismo relacional, turismo de naturaleza, ecoturismo, agroturismo, turismo cultural, turismo deportivo y de aventura, turismo de salud, etc.), con otros productos turísticos importados del medio litoral y urbano (turismo de golf, turismo de negocios, turismo de congresos, turismo residencial, etc.). Pero la amalgama de productos turísticos presentes en los espacios interiores no queda ahí, ya que, junto a la combinación de productos tradicionales de índole rural, natural, urbana y litoral, están apareciendo con fuerza toda una serie de nuevos productos emergentes o en proceso de consolidación como el enoturismo, el turismo industrial, el turismo especializado y, posiblemente, en un futuro inmediato, otros como el turismo arqueológico, el turismo idiomático y, por qué no, el turismo de cruceros si se siguen mejorando las vías y los medios de comunicación hacia el interior.

Llegados a este punto, merece la pena detenerse en el concepto de turismo alternativo, tan habitualmente asociado al turismo de interior y que se popularizó a partir de los años noventa del siglo pasado. Ivars (2000) analiza este concepto indicando que las crecientes críticas a los desarrollos turísticos masivos del litoral han desembocado en la enunciación de diferentes turismos «alternativos», entre los que se incluye en numerosas ocasiones el turismo rural (véase la tabla 1). No obstante, el autor matiza la cuestión indicando que, en primer lugar, el turismo alternativo nunca podrá sustituir al turismo masivo convencional, ni reemplazar su repercusión económica, social, ambiental o política (Butler, 1992). Es más, muchos turismos alternativos basan su desarrollo en la complementariedad derivada de las infraestructuras y los equipamientos turísticos, creados inicialmente para atraer al turismo masivo (Butler, 1992; Pearce, 1992). En segundo lugar, las características en las que se apoya el turismo alternativo (desarrollo gradual, control local, respeto medioambiental, etc.) no son una alternativa, sino que, con la actual situación de los recursos y los mercados turísticos, son la única posibilidad real (Pearce, 1992) de desarrollo a largo plazo de todos los productos turísticos, sin excepción.

Tabla 1. Principales diferencias entre el turismo de masas y el turismo alternativo

\begin{tabular}{|c|c|}
\hline Turismo de masas & Turismo alternativo \\
\hline Turismo costero de alta densidad. & Turismo disperso de baja densidad. \\
\hline Gran escala. Integrado. & Pequeña escala. Doméstico. \\
\hline Propiedad multinacional. & Propiedad local, familiar. Pequeños negocios. \\
\hline Volumen de mercado alto. & Volumen de mercado bajo. \\
\hline Existe un mercado dominante. & No hay un mercado dominante. \\
\hline $\begin{array}{l}\text { Actividades: playa, vida nocturna, } \\
\text { comercio. }\end{array}$ & $\begin{array}{l}\text { Actividades: naturaleza, cultura, gastronomía, } \\
\text { artesanía. }\end{array}$ \\
\hline Estacionalidad: verano. & No hay estación dominante. \\
\hline Estancia: larga-media. & Estancia: media-corta. \\
\hline Dominio económico del sector turístico. & Dominio económico de sectores complementarios. \\
\hline No retención de beneficios. & Retención de beneficios. \\
\hline
\end{tabular}

Fuente: elaboración propia a partir de Weaver (1991). 
Por otro lado, hay que insistir en que no es lo mismo turismo de interior que turismo rural, aunque, en el ámbito mediterráneo, habitualmente coincidan. Ambos conceptos son polisémicos y de significado impreciso, según el uso que se hace de cada acepción. Los términos pueden aparecer instalados en distintos ámbitos o contextos que les confieren significados específicos y no siempre coincidentes. Así, en las relaciones cotidianas, se les da un significado; en el mercado turístico, adquieren un sentido específico; en el marco de la gestión pública, se les define en términos operativos e instrumentales; en la academia, se debaten sus acepciones, y en los medios de comunicación, se recogen distintas percepciones (Vera et al., 2011). A pesar de todo, se puede dilucidar que la diferencia principal entre turismo de interior y turismo rural proviene del hecho de que el turismo rural, que no deja de ser parte de los turismos de interior, fundamenta su desarrollo en la preservación del hábitat y de la actividad habitual de las poblaciones receptoras (Reyna, 1992). Sin embargo, existe el riesgo de que esta premisa no se cumpla cuando se desarrolla un turismo rural indiscriminado, conducido esencialmente por impulsos de mercado y basado en la explotación intensiva de los recursos tradicionales. La sostenibilidad de este modelo de desarrollo rural dependerá en buena medida del grado de integración de las nuevas dinámicas territoriales, sociales, económicas y ambientales que trae de la mano el turismo y de su armonización con los modelos históricos de organización del medio rural. Será importante que se evite la simple superposición de funciones (Sancho y Vera, 2008).

El turismo en espacios rurales es el resultado de una conjunción de factores en las sociedades posindustriales, al asentarse nuevas tendencias de consumo recreativo que se han venido a denominar "posturísticas». Estos cambios sociales y culturales derivan de un nuevo imaginario del consumo de turismo y ocio. A través de este imaginario colectivo, se transforma un lugar neutro en un destino turístico; un ejemplo de este redescubrimiento de lugares, desde el prisma antropológico y social, es el turismo rural. La conversión del espacio y del patrimonio rural para un uso turístico se ha hecho recurriendo a valores como la autenticidad, la identidad cultural y la etnicidad (Cànoves y Villarino, 2000).

Desde el punto de vista territorial, quizás, el mayor déficit del turismo rural esté en la falta de un modelo territorial que le dé consistencia, más allá del comportamiento mimético que se produce con cierta frecuencia respecto de los municipios del litoral español, que empieza a poner en peligro algunos de estos destinos. La ausencia de planificación inicial y la reacción especulativa a los incrementos exponenciales de la demanda, no siempre turística, está llevando a situaciones no deseadas que, en cualquier caso, se escapan del ideal de esta tipología turística. En este sentido, los agentes turísticos en general, pero sobre todo los gobiernos y los empresarios locales, deben asumir un mayor compromiso con los valores del territorio. Deben buscar fórmulas de cooperación en aras a la consecución de un desarrollo turístico competitivo, no por volumen, sino por la calidad de la experiencia vivida por el turista y la sostenibilidad de la propia actividad turística (Pulido y Cárdenas, 2011). 
Tabla 2. Principales modalidades turísticas presentes en los espacios interiores

\begin{tabular}{lll}
$\begin{array}{l}\text { Productos tradicionales } \\
\text { ligados al medio rural y natural }\end{array}$ & $\begin{array}{l}\text { Productos emergentes o } \\
\text { en proceso de consolidación }\end{array}$ & $\begin{array}{l}\text { Productos importados } \\
\text { del medio litoral o urbano }\end{array}$ \\
\hline $\begin{array}{l}\text { Turismo rural de retorno } \\
\text { o veraneante. }\end{array}$ & $\begin{array}{l}\text { Turismo industrial. } \\
\text { Enoturismo. }\end{array}$ & $\begin{array}{l}\text { Turismo residencial. } \\
\text { Turismo de golf. }\end{array}$ \\
$\begin{array}{l}\text { Turismo rural relacional. } \\
\text { Agroturismo. }\end{array}$ & $\begin{array}{l}\text { Turismo especializado. } \\
\text { Turismo de negocios. }\end{array}$ \\
$\begin{array}{l}\text { Ecoturismo. } \\
\text { Turismo de naturaleza. }\end{array}$ & & \\
Turismo de salud y belleza. & & \\
Turismo activo (deportivo & & \\
o de aventura). & & \\
Turismo cultural. & & \\
\hline
\end{tabular}

Fuente: elaboración propia.

Una vez aclarados los aspectos conceptuales anteriores, retomamos de nuevo el hilo conductor del enfoque multiproductivo del turismo de interior. Cabe puntualizar que, en algunos casos, los productos turísticos emergen totalmente desvinculados y al margen de los procesos del turismo litoral, y en otros, por el contrario, fuertemente relacionados con el turismo de sol y playa, con lo cual desempeñan un mero papel complementario. Así, de forma particular y atendiendo a las características inherentes de cada espacio interior, la gama de productos turísticos presentes puede aumentar según el potencial de cada territorio o bien según el grado de accesibilidad con respecto al litoral.

Aunque de forma general, se pueden distinguir fundamentalmente tres tipologías turísticas en función de la generación de rentas rurales y el impacto sobre el desarrollo local: 1) agroturismo, donde el responsable es la misma unidad productiva agropecuaria que ejecuta y organiza las actividades; 2) turismo rural, cuando la actividad se origina en el campo, no necesariamente en una unidad agropecuaria, aunque las rentas de igual modo se acumulan en el ámbito rural, y 3) turismo en el espacio rural, cuando la organización y la ejecución escapan del medio rural, que pasa a ser un mero soporte físico de las actividades, y las rentas generadas se desvían hacia el medio urbano (aquí no existiría verdadero desarrollo rural). De forma particular y atendiendo a las características propias de cada espacio interior, la gama de modalidades turísticas presentes puede aumentar considerablemente según el potencial turístico de cada territorio, la capacidad de desarrollo y el grado de complementariedad entre el amplio abanico de productos turísticos disponibles (tabla 2).

\section{Productos tradicionales ligados al medio rural y natural}

El turismo tradicional rural se concibe como la primera y más espontánea forma de turismo rural. Aparece con una connotación de retorno al campo por parte de los hijos y nietos de las personas que participaron en el éxodo 
rural hacia las grandes ciudades. Según Yepes (1995): «[...] es un turismo con una demanda cautiva, fiel, poco exigente con el medio, con niveles de gasto y actividades complementarias moderados, y que es propietaria o lo será por vínculos familiares, de una gran parte del patrimonio inmobiliario de los pueblos».

\subsection{El turismo rural de retorno o veraneante ${ }^{2}$}

En la actualidad, el concepto de turista tradicional ha dejado paso a los conceptos de turista de retorno y turista veraneante, que, aunque son bastante similares, presentan algunos matices diferentes. Los turistas de retorno son personas que poseen unos estrechos lazos afectivos y familiares con el municipio rural, por tratarse de emigrantes o descendientes de emigrantes que lo abandonaron durante el éxodo rural. Normalmente, estos turistas no necesitan pagar su alojamiento, ya que disponen de vivienda propia o bien se hospedan en casa de familiares. Según López Colás (2003), el turismo de retorno es un fenómeno que se produce tras la emigración del campo a la ciudad. Esta tipología turística se manifiesta en los lugares donde se ha producido este hecho y su intensidad está vinculada a la cantidad de población emigrante. La Organización Mundial del Turismo lo cataloga como turismo "de raíces» o "nostálgico», sin especificar que sea de interior o ni siquiera rural. Sin embargo, en buena parte del interior peninsular se asocia al éxodo producido en la primera parte de la segunda mitad del siglo xx, que ha movilizado un turismo al que algunos autores denominan «doméstico» (Manero, 1997), frente al componente cognitivo del turismo reglado (Santana, 2006). Los «turistas retornados» están básicamente constituidos por el emigrante y su familia. El aumento del tiempo libre y la mejora de las rentas consolidan ese turismo para una parte del periodo vacacional. Ello se plasma en el establecimiento de una segunda residencia y, consecuentemente, en un fenómeno de turismo residencial en los pueblos de origen (Cebrián y García González, 2009).

Por su parte, el turista veraneante es el residuo del antiguo veraneante de los años 60 del siglo pasado, que buscaba en el interior y sobre todo en las áreas de montaña, la salubridad que no podía encontrar en las urbes más masificadas. En la actualidad, está apareciendo un nuevo segmento dentro de esta tipología: los extranjeros que compran pequeños terrenos urbanizables o rehabilitan casas en los centros históricos del ámbito rural en busca de tranquilidad, autenticidad y un menor coste tanto de vida como de adquisición de viviendas. Ambos tipos de turistas desarrollan una estancia media prolongada, que se puede incrementar notablemente si la vivienda es propia. El gasto medio por persona y día es bastante reducido, ya que se ciñe básicamente al consumo de bienes de primera necesidad y ocio.

2. Este apartado es una adaptación del texto de contenidos similares publicado por Cebrián y García González (2009). 


\subsection{El turismo rural relacional}

Según un informe publicado por la Generalitat Valenciana (2005) sobre el turismo rural valenciano, «los turistas que hacen uso de esta modalidad turística son aquellos que visitan el entorno rural para generar o mantener relaciones familiares o de amistad en un marco diferente al ambiente urbano cotidiano", caracterizado por el individualismo y la autosuficiencia. En este sentido, según el susodicho informe se pueden diferenciar tres perfiles de turistas dentro del turismo relacional: «turistas relacionales jóvenes» que practican el turismo de parejas o grupos de amigos buscando un marco adecuado para la relación (habitualmente se demandan entornos naturales donde se puedan practicar actividades deportivas y de aventura); "turistas relacionales familiares» que practican un turismo de familias o varias parejas de amigos con niños, buscando un espacio más seguro y tranquilo (habitualmente demandan recursos culturales y gastronómicos), y «turistas relacionales de pareja» que buscan un medio más relajado, idílico e íntimo para afianzar los lazos afectivos con su cónyuge (habitualmente estos turistas demandan entornos naturales de belleza paisajística y alojamientos con encanto o alta calidad).

Básicamente, se trata de un turismo de proximidad dentro de la comunidad autónoma o procedente de provincias limítrofes. La estancia media de los turistas suele ser elevada, aunque puede variar notablemente en función del perfil del turista y del tipo de alojamiento elegido (mayor estancia en viviendas en alquiler y menor en alojamientos rurales reglados). Sin embargo, la estacionalidad suele ser muy acusada, ya que las estancias se concentran fundamentalmente en verano, puentes, Semana Santa y Navidad.

\subsection{El agroturismo}

El agroturismo es una modalidad específica de turismo, casi siempre identificada con el turismo rural, y que puede definirse como «aquel conjunto de actividades turísticas y de ocio propuestas y realizadas por titulares o responsables de explotaciones agrarias, activos o jubilados, que tengan alguna relación con la explotación agraria y que vayan destinadas a un cliente mayoritariamente urbano» (Cors, 2007).

La agricultura en el espacio rural no cumple únicamente con funciones de naturaleza productiva (primaria o secundaria), sino también funciones territoriales y ambientales. A este tenor, son meritoriamente destacables dos funciones: por un lado, la repercusión del sistema agrario en la calidad y la peculiaridad de la oferta derivada de las actividades terciarias, y dentro de ellas las recreativas, y, por el otro, la capacidad de los sistemas agrarios para crear paisaje (Sayadi, 1998). Así, el agroturismo es un producto turístico eminentemente rural, que se localiza en las explotaciones agropecuarias (granjas, granjas escuela, masías, caseríos, etc.) y que hace al turista espectador de primer orden o partícipe, si es su deseo, en los quehaceres cotidianos de la explotación. Aquí el campesino hace de anfitrión y mentor del turista, al cual le proporciona además alojamiento y pábulo. 
Cabe señalar que el agroturismo como oferta turística diferenciada surge en Europa en la década de 1960. Italia és el país donde se alcanza un desarrollo más notable. En sus comienzos, Velluti (1988) define el agroturismo como «la hospitalidad de los agricultores en alojamientos restaurados a partir de antiguos edificios rurales y en espacios al aire libre para el camping, los servicios de alimentación o comidas a base de productos de la explotación y las actividades culturales y de ocio realizadas por los turistas en las explotaciones agrarias». En España el agroturismo es aún escaso, aunque tiene una cierta entidad y desarrollo en Cataluña, País Vasco y Baleares (Tuñón, 1992).

Según Calatrava (2001), la integración del turismo y la agricultura encuentra su fundamento en una amplia gama de argumentos. Por ejemplo: porque la familia agraria pluriactiva puede ofrecer servicios turísticos, asimismo porque la "cultura de lo agrario" puede ser un atractivo turístico o bien porque el turismo rural genera una demanda de productos agrarios que puede ser importante para el fomento de la agricultura en la zona. En este sentido, el turismo puede favorecer las actividades agroartesanales, que, a su vez, inciden favorablemente sobre la agricultura local. Por otro lado, el turismo puede actuar como factor de estabilidad laboral para la mano de obra agraria al cumplir una triple acción (incrementar rentas, crear infraestructuras y generar empleo), a lo que ayuda que el efecto multiplicador del turismo puede fomentar otras actividades económicas que incidan favorablemente sobre el sector agrario. Un último argumento sería que la desaparición de la agricultura tendría efectos negativos sobre el turismo (los cambios en el paisaje supondrían una pérdida de atractivo, los cambios de humidificación afectarían al ecosistema, se incrementaría el peligro de incendios forestales, no se dispondría de productos típicos, etc.).

El mundo rural puede encontrar en el agroturismo un aliado que contribuya a diversificar y reactivar la economía y la sociedad, conserve los espacios y la arquitectura popular, mejore los equipamientos y potencie los productos y las tradiciones locales, constituya una fuente directa de ingresos y un medio de creación de empleos complementarios o alternativos a la agricultura y una forma de mantener la población en el medio rural (Yepes, 1995). En este sentido, son numerosas las ventajas que otorga la complementariedad entre la agricultura y el turismo, siempre y cuando no se entre en conflicto o competencia. La subordinación absoluta al turismo supeditaría la explotación agropecuaria a la vulnerabilidad de los cambios de la demanda y generaría, con la pérdida de las actividades agropecuarias menos rentables, el desmantelamiento del auténtico reclamo que motiva el interés de los turistas.

Como bien señalan Sayadi y Calatrava (1997), el agroturismo puede ser importante para el futuro de determinados procesos del desarrollo rural, sobre todo si se entiende que el mantenimiento de las actividades agrarias permite que se conserve el paisaje modelado por éstas y el patrimonio histórico y cultural del mundo rural (tipos de cultivos y explotaciones, hábitats y arquitecturas típicas, etc.). Asimismo, el agroturismo contribuye a la revalorización de los productos locales (se demandan productos agrarios naturales o ecológicos, productos elaborados de forma tradicional o artesanal, productos típicos 
de un espacio concreto, etc.). La agricultura proporciona un rico patrimonio etnográfico digno de ser admirado (herramientas y utensilios, maquinarias y aperos agrícolas, oficios y talleres artesanales, forja, cantería, espartos, bodegas, almazaras, hornos, etc.). Pero, también, el agroturismo contribuye a armonizar los intereses agrarios y la protección del medio ambiente a través de la gestión integrada del territorio en pro de la colectividad.

\subsection{El ecoturismo}

Desde que el bosque se considera teniendo en cuenta una óptica más global (productiva, social y ambiental), empiezan a aparecer nuevos usos que escapan de la mera producción maderera. A partir de entonces, se empieza a hablar de la tercera dimensión del bosque (Susmel, 1968), que no es otra que una nueva función de uso social o recreativo estudiada por biólogos (Gómez-Limón y de Lucio, 1995), geógrafos (Valenzuela, 1984; Font y Tribe, 2000; Donaire y Gordi, 2003) y forestales (Hermanin et al., 1988), entre otros.

Uno de los primeros autores en definir el concepto de ecoturismo de forma integral fue Ceballos $(1993)^{3}$, indicando que se trata de:

Aquella modalidad turística ambientalmente responsable consistente en viajar o visitar áreas naturales sin mayores perturbaciones con el fin de disfrutar, apreciar y estudiar los atractivos naturales (paisaje, flora y fauna silvestres) de dichas áreas, así como cualquier manifestación cultural (del presente o del pasado) que pueda encontrarse ahí, a través de un proceso que promueve la conservación. Tiene bajo impacto negativo ambiental y cultural, y propicia participación activa y socioeconómicamente benéfica de las poblaciones locales. (Ceballos, 1993)

No obstante, existen otros autores que no consideran que el ecoturismo sea tan amplio y proporcionan definiciones más concretas. En este sentido, Blangy (1995) indica que ecoturismo sería la actividad turística «que se desarrolla en espacios poco perturbados por el hombre y que debe contribuir a la protección de la naturaleza y al bienestar de las poblaciones locales». Boo (1993) restringe aún más la definición anterior, identificando tres funciones que debe cumplir el ecoturismo para contribuir a la conservación del medio ambiente: creación de fondos para la protección de las áreas naturales visitadas, creación de empleos para las localidades limítrofes con las zonas protegidas y contribución a la educación medioambiental de los visitantes. Por su parte, Buckley (1994) destaca que el concepto de ecoturismo varía según sea definido por organizaciones ecologistas, administraciones públicas o empresas. Este autor propone una definición restrictiva que englobe productos basados en la naturaleza, que contribuyan a financiar la conservación, que se gestionen de manera sostenible y que fomenten la existencia de un turista consciente

3. Esta definición fue posteriormente utilizada por la UICN (Unión Mundial para la Naturaleza) en 1996. 
y responsable. Al respecto, Ivars (1996) matiza que el término ecoturismo se aplica generalmente al turismo en espacios con figuras legales de protección (parques nacionales, parques naturales, etc.) y es análogo a otros términos. Estos términos incluyen en numerosas ocasiones atributos que son propios de la gestión, tales como turismo sostenible. Otros, sin embargo, hacen mayor hincapié en el comportamiento de los turistas: turismo blando, turismo verde o turismo consciente y responsable, etc.

Según Merg (1999), la definición que se ha vuelto un estándar ampliamente utilizado es la que expone Honey (1999). Esta autora indica que:

El ecoturismo es el viaje a áreas frágiles, prístinas y habitualmente protegidas, que se esfuerzan por ser de bajo impacto y (normalmente) de pequeña escala. Ayuda a educar a los viajeros; provee de fondos para la conservación; directamente beneficia el desarrollo económico y el fortalecimiento político de las comunidades locales; y promueve el respeto por las diversas culturas y los derechos humanos. (Honey, 1999)

Además, establece una distinción entre dos tipos de ecoturismo: «el ecoturismo genuino, busca poner en práctica los múltiples principios del ecoturismo, dentro de un sólo proyecto, compañía o parque. El ecoturismo light busca adoptar sólo una fachada, sin hacer los cambios fundamentales al turismo de masas». Asimismo, Honey (1999) identifica los siete principios fundamentales que deben guiar el ecoturismo: involucrar viajes a destinos naturales, minimizar impactos, promover la conciencia ecológica, proveer beneficios financieros directos a la conservación, proveer beneficios financieros y el fortalecimiento a las comunidades locales, respetar la cultura social y apoyar los derechos humanos y los movimientos democráticos. Por su parte, Fennell (1999) aglutina quince definiciones previas de ecoturismo en la siguiente:

El ecoturismo es la forma sustentable de turismo basada en los recursos naturales, que se dedica principalmente a experimentar y aprender sobre la naturaleza, y que se maneja éticamente para ser de bajo impacto, no consumista y localmente orientada (la administración, los beneficios y la escala). Ocurre típicamente en áreas naturales y debe contribuir a la conservación o preservación de tales áreas. (Fennell, 1999)

Más recientemente, Blázquez (2005) alerta de que, aunque la prestación de servicios turísticos proporciona beneficios económicos y contribuye a la conservación del patrimonio natural, al mismo tiempo pone en uso los reductos intocados de naturalidad, precisamente los que sostienen el equilibrio ecológico y que son el referente simbólico e ideológico del ecologismo como actitud de denuncia a la insostenibilidad. Así, incorporar estos espacios al carrusel de la comercialización y de la sobreexplotación puede representar la muerte de éxito del ecologismo, porque maltinterpreta su denuncia y atiende únicamente a sus aspectos «territorialistas». 


\subsection{El turismo de naturaleza}

Según Ceballos (1993): «el turismo de naturaleza abarca todo el turismo directamente dependiente del uso de recursos naturales que no han sido significativamente transformados, incluso si el uso de los recursos naturales por parte del turista no es sabio o sustentable. Incluye actividades tales como la cacería, motociclismo de montaña, ciclismo de montaña y descenso de rápidos». No obstante, se puede señalar que, dentro de este producto, se pueden diferenciar dos subproductos turísticos diferentes: el turismo de naturaleza activo y el turismo de naturaleza especializado.

\section{El turismo de naturaleza activo}

Este subproducto presenta como principales motivaciones la realización de actividades recreativas y de esparcimiento en la naturaleza a través de la práctica de actividades deportivas de intensidad física diferente, entre las que cabe destacar, por su profusión, el senderismo. Sin embargo, la consolidación del turismo rural y el senderismo como actividad económica exige superar los esquemas del turismo convencional y, en base a principios de planificación y comercialización, elaborar productos competitivos que vayan más allá de la mera oferta de alojamiento y que además cumplan los requisitos de sostenibilidad y respeto al medio natural y social (Antón y López, 1996; López Monné, 1998).

\section{El turismo de naturaleza especializado}

Este subproducto aparece mucho más ligado a la concepción de ecoturismo y presenta como principal motivación la contemplación, el disfrute y el conocimiento de aspectos específicos de los espacios naturales protegidos por medio de la realización de actividades físicas de baja intensidad, sin generar afecciones o impactos sobre los recursos naturales.

\subsection{El turismo de salud y belleza}

Este producto turístico es uno de los de mayor tradición y recorrido histórico de los presentes en el medio rural. Esta forma de hacer turismo se diferencia del resto fundamentalmente por la motivación de la demanda, en este caso encaminada hacia la búsqueda del bienestar físico y psíquico a través de terapias y tratamientos naturales con aguas a las que se les atribuyen ciertas propiedades beneficiosas para la salud. De este modo, se ofrecen al turista toda una serie de actividades asociadas a la hidroterapia (aguas minero-medicinales) y a la talasoterapia (utilización de los beneficios del medio marino que comprenden el clima marino, el agua del mar, los barros marinos, algas y otras sustancias extraídas del mar). El agua se emplea no sólo para el tratamiento de enfermedades, sino también como un elemento favorecedor del relax, el bienestar y la belleza. En la variante de belleza y relax, el agua se entiende más como un elemento de salud y confort. En este sentido, se ofrecen infinidad de programas para que los turistas logren aproximarse a los actuales cánones de belleza 
(adelgazamiento, puesta en forma, cuidados de la piel, etc.) y de relax (masajes corporales, duchas, tratamientos de algas, etc.).

En la actualidad, la mayoría de las ofertas sobre turismo de salud (hoteles clínica, hoteles de reposo o centros de talasoterapia, climatoterapia o fisioterapia), se encuentran en el litoral asociados a complejos hoteleros de categoría superior, aunque el interior sigue presentando magníficas posibilidades para el desarrollo de esta actividad en sus centros tradicionales y en los nuevos spas urbanos. La demanda que hace uso de este producto turístico es también muy variada: demanda urbana con alto poder adquisitivo en busca de una nueva forma de hacer turismo que combine descanso y mejora de la salud mental y corporal, personas con necesidades concretas en materia de rehabilitación y beneficiarios del «termalismo social» (personas mayores de 65 años que precisan tratamientos termales y que obtienen financiación a través de las diferentes administraciones públicas para sus estancias).

\subsection{El turismo activo}

A la hora de definir el turismo activo, sobre todo en su vertiente de aventura, se deben considerar varios elementos fundamentales, entre los que destacan actividad, motivo, riesgo, experiencia y medio ambiente.

- Actividad: Hall (1989) define el turismo de aventura como «un amplio espectro de actividades turísticas al aire libre, $[. .$.$] que suponen una interac-$ ción con el ambiente natural lejos del hogar del participante y que contiene elementos de riesgo donde el participante, el escenario y el manejo de la experiencia del participante influyen en el desenlace». Otras definiciones que atienden fundamentalmente a la práctica de actividades son aportadas por Progen (1979); Darst y Armstrong (1980) y Yerkes (1985).

- Motivo: Iso-Ahola (1980) fue uno de los primeros autores que explicó los motivos fundamentales por los que las personas participan del ocio al aire libre. Claramente, distingue dos dimensiones: «un intento para lograr algo» y «un intento para evitar algo». Por su parte, Ewert (1989) sostiene que, en el caso del turismo de aventura, debe incluir una tercera dimensión: «la toma de riesgo». Manning (1986) apunta que los motivos para participar en una actividad de aventura al aire libre por lo general consisten de un deseo de logro, afiliación, control, escape y conocimiento de uno mismo.

- Riesgo: Ewert (1989) sostiene que el concepto de toma de riesgo es esencial para las actividades de turismo de aventura. En este sentido, se puede predecir que la ausencia de riesgo puede traducirse en una disminución en la satisfacción, como también en un aumento en el deseo por participar. Como tal, se considera que el riesgo es un elemento importante, al distinguir entre las actividades de aventura al aire libre y otras actividades recreativas exteriores que no se basan en la aventura (Meier, 1978; Ewert, 1987; Ewert y Hollenhorst, 1989).

- Experiencia: Según Sung et al. (1996), la experiencia de aventura al aire libre ha sido conceptuada de varias maneras y, por lo general, atiende a dos 
ideas: «riesgo percibido» y «competencia percibida». Ewert y Hollenhorst (1989) describen tales experiencias como "una búsqueda de competencia» unidas con «la valoración del riesgo y el peligro».

- Medio ambiente: «El turismo de aventura utiliza el entorno o medio natural como recurso para producir sensaciones de descubrimiento en sus participantes. Su objetivo básico es transmitir estas sensaciones y así necesita espacios poco utilizados turísticamente. El turismo deportivo es la forma de turismo que utiliza cualquier actividad deportiva [...], donde el espectáculo y las sensaciones de riesgo son fundamentales como reclamo turístico» (García Henche, 2003).

Asimismo, aparte de los elementos principales del turismo de aventura anteriormente expuestos, el marco fundamental para definir este producto turístico debe incluir los conceptos «aventura» $\mathrm{y}$ «viaje». Una definición global del turismo de aventura debe contar con un equilibrio razonable de los dos conceptos aludidos. En consecuencia, la definición que mejor viene a integrar todos los aspectos anteriormente citados es la que aporta Sung et al. (1996), que define el turismo de aventura como el «viaje o excursión con el propósito específico de participar en las actividades para explorar una nueva experiencia que, por lo general, supone el riesgo advertido o peligro controlado asociado a desafíos personales, en un medio ambiente natural o en un exótico escenario al aire libre».

El perfil más característico de este tipo de turista activo es el de jóvenes de entre 18 y 40 años, con nivel económico medio-alto, estilo de vida activo y personalidad inquieta. Estos turistas suelen provenir de núcleos urbanos próximos al destino, habitualmente dentro de la propia provincia o comunidad autónoma. La organización del viaje se suele llevar a cabo a través del contacto directo con las propias empresas organizadoras de actividades. Internet y el marketing directo son los dos canales de información básicos. No obstante, también existe la posibilidad de contratar paquetes integrados de servicios (guía, alojamiento, actividades, materiales y equipos, etc.), ofrecidos por empresas especializadas en este segmento turístico. Por norma general, las estancias son de corta duración y existe un bajo nivel de repetición de las visitas a un mismo destino, dada la predilección de este tipo de turista por descubrir nuevos destinos y nuevas experiencias. Por el contrario, la estacionalidad de este producto es escasa, ya que estos deportes pueden practicarse durante todo el año, es más, incluso se suelen evitar los periodos de temporada alta, de modo que el turista fragmenta sus vacaciones y realiza viajes cortos pero muy frecuentes.

La práctica masiva de ciertas actividades en zonas rurales puede ser considerada como un nuevo peligro para la conservación medioambiental. Resulta evidente que algunas actividades turístico-deportivas llegan a producir fuertes impactos negativos en los entornos naturales, como ruidos y aglomeraciones de tráfico, generación de residuos, deterioro de caminos, de pistas forestales y de senderos, etc. No obstante, el impacto ambiental de estas actividades también varía en función de otros factores como el número de practicantes, la educación ambiental de los mismos y la capacidad de carga del lugar. Por todo ello, resulta 
fundamental regular las empresas que organizan este tipo de actividades, con una triple intención: conservar el medio natural y la biodiversidad, proteger a los usuarios y crear negocios de calidad (García Saura, 2010).

\subsection{El turismo cultural}

Según García Henche (2003): «el turismo cultural es el basado en la utilización de los recursos culturales de un territorio (recursos artísticos, históricos, costumbres...), orientándose hacia la preservación y el fomento de los mismos. Desde una aldea hasta una gran ciudad pueden constituir el ámbito de desarrollo de esta forma de turismo».

El rápido crecimiento del turismo y la vertiginosa diversificación de los productos de este tipo se suman al aumento del valor de la cultura en el imaginario social. Estos procesos han ayudado a que los bienes de patrimonio cultural sean considerados también como recursos turísticos, tanto por el sector turístico como por los propios ciudadanos. Ello representa una magnífica oportunidad para mejorar la consideración social de dichos bienes, renovar un uso social que, en la mayoría de los casos, se había perdido y, además, captar fondos para mejorar su conservación y gestión (Velasco, 2009).

El turismo cultural puede ejercerse de forma pasiva, a través de la contemplación del patrimonio histórico y artístico de una localidad, o bien de forma activa, por medio de la involucración y la participación vivencial en el folclore lúdico-festivo de un lugar. Tradicionalmente, la visita a museos se realizaba de forma pasiva, pero en la actualidad se tiende a establecer una mayor interacción con el turista a través de talleres, disfraces de época, traducciones de textos, degustaciones, fabricación y compra de recuerdos. Otras actividades dignas de mención son las rutas y excursiones culturales, la asistencia a eventos (teatro, música, conciertos, ferias, etc.), las degustaciones gastronómicas y las festividades locales de interés turístico, sobre todo nacional e internacional.

La organización de este tipo de viajes se suele realizar de forma individual y, cada vez más, a través de Internet. No obstante, en el caso de turistas extranjeros (sobre todo británicos), se contratan paquetes turísticos a touroperadores especializados en el segmento cultural. Habitualmente, las estancias de los turistas que consumen este producto suelen ser en hoteles y de corta duración, siempre inferior al turismo vacacional. Sin embargo, la estacionalidad es baja, dada la elevada dispersión de los viajes durante cualquier época del año, en algunas ocasiones buscando la coincidencia con eventos y festividades concretas en los destinos seleccionados.

\section{Productos emergentes o en proceso de consolidación}

\subsection{El turismo industrial}

El turismo industrial se puede definir como la actividad que se realiza visitando centros industriales (fábricas, talleres, almacenes, etc.) para completar la cultura del turista y como una manera de ampliar la actividad económica de los 
pueblos (Calabuig y Ministral, 1994). En concreto, se trataría de actividades turísticas sobre «lugares hechos por el hombre» (man made sites), construcciones $y$ terrenos que tienen su origen en los procesos industriales de épocas anteriores o actuales. A partir del pasado industrial, es posible realizar iniciativas cuyos objetivos deben ser culturales, haciendo accesible al público un patrimonio industrial de enorme potencial, sensibilizando a los visitantes con la diversidad y la riqueza de la actividad industrial y los problemas medioambientales que las empresas (por ejemplo, extractivas) han generado, pero también se puede hablar de objetivos educativos, sobre todo dirigidos a niveles primarios y secundarios, al despertar el interés de los jóvenes por las múltiples facetas de la ciencia, la tecnología y los procesos de desarrollo relacionados con el sistema industrial y minero (Paz y Visvequi, 2001).

El patrimonio industrial que visitan los turistas está formado por inmuebles (zonas de producción, de viviendas, etc.), los muebles (maquinaria, archivos, herramientas, etc.) y el tipo de vida de los trabajadores, el know-how de los procesos productivos, etc. Desde mediados de los años ochenta, se han convertido en objeto de atención y visita no sólo los establecimientos industriales antiguos, sino también las grandes instalaciones industriales y los establecimientos científicos. En torno a estos recursos patrimoniales, empiezan a aparecer toda una serie de museos científico-técnicos especializados en temáticas muy concretas (navegación, agricultura, radio, óptica, fotografía, automóvil, ferrocarril, artesanía, dirigibles, motocicletas, electricidad, juguetes, papel, etc.). Todos estos recursos se contemplan como una alternativa para un nuevo modelo de desarrollo local, que puede ayudar a superar un periodo de recesión económica, demográfica y social, cuando desaparecen las actividades productivas tradicionales y no son rápidamente sustituidas por otras (Llurdés, 1995).

Sin embargo, no es fácil activar los bienes industriales como elementos patrimoniales aptos para el aprovechamiento turístico. En este sentido, Soyez (1993) reúne a los tres grandes grupos de barreras que se pueden encontrar:

- Cognitivas: la industria no es un bien cultural, no tiene valores estéticos, no es interesante, unido a que la visita de este tipo de instalaciones no es elegante a priori.

- Económicas: los dueños de las instalaciones obsoletas pueden pensar que es más rentable vender la maquinaria como chatarra, o enajenar el terreno, o dedicar el edificio a otras ocupaciones. Pueden presentarse también dificultades para el cambio de funciones y el coste de la restauración resulta elevado.

- Legales o administrativas: hay competencias poco claras sobre las actuaciones que se deben realizar.

- Físicas: lejanía de algunas instalaciones respecto a las rutas turísticas tradicionales e incluso problemas de atención sanitaria con relación a potenciales accidentes.

Los principales usuarios de este producto turístico son escolares, visitantes locales, turistas de proximidad y excursionistas. Las principales motivaciones 
son la búsqueda del significado histórico de los lugares de producción industrial antigua, el conocimiento de un medio extraño y diferente del que existe hoy en día en la ciudad, el interés por comprender algunos funcionamientos técnicos en desuso o la profundización nostálgica en una época y unas formas de vida ya perdidas (Pardo, 2010). Sin embargo, este tipo de turismo todavía se caracteriza por generar estancias muy cortas en destino o excursiones diarias de tipo colectivo.

\subsection{El enoturismo}

El enoturismo se puede definir como el turismo que nace y se desarrolla en base a la cultura del vino, desde las visitas a bodegas hasta todo aquello que gira en torno a las tradiciones y los paisajes que rodean al mundo del vino. Esta modalidad turística representa simultáneamente un comportamiento del consumidor, una estrategia para desarrollar el área geográfica y el mercado del vino de una zona y una oportunidad de promoción de las bodegas para vender sus productos directamente a los consumidores (Getz y Brown, 2006; Rodríguez et al., 2010). En definitiva, el turista enológico busca el conocimiento de la cultura de la tierra, de las manifestaciones artísticas, de su historia, de la gastronomía y el disfrute de los paisajes que enmarcan todo el producto enoturístico. Por todo ello, esta tipología turística es un potente dinamizador de la economía de las zonas periféricas.

En concreto, el producto enoturista se caracteriza por la realización de toda una serie de actividades vinculadas al mundo del vino: visitas a bodegas, cursos de cata, etc. Asimismo, estas actividades pueden complementarse con la gastronomía, la cultura y la naturaleza del lugar. El perfil del turista es variado, con edades medias, de clase social alta y habitualmente procedente de ámbitos urbanos. La organización del viaje se realiza a través de las bodegas o asociaciones que gestionan las diferentes rutas del vino. El gasto durante la estancia se reparte entre actividades relacionadas con el vino y otros conceptos como compras, restaurantes, visitas, etc. Las estancias suelen ser a lo largo de todo el año, sobre todo durante fines de semana y los periodos de vendimia.

\subsection{El turismo especializado}

Casillas (1995) define el turismo especializado como «la modalidad de turismo en la que el turista busca profundizar en el conocimiento de un aspecto específico del territorio visitado y en el que es, en alguna medida, un "experto"». El turismo especializado es una especie de concepto paraguas bajo el que tendrían cabida una amplia gama de productos turísticos de interior, tales como el enoturismo, el ecoturismo, el turismo deportivo o el turismo cultural. Sin embargo, ello no quiere decir que todos los turistas que consumen estos productos se puedan incluir dentro de esta modalidad, ya que únicamente formarán parte del turismo especializado aquellos segmentos de demanda que presenten mayores niveles de formación, conocimientos y exigencias en cada tema concreto. 


\section{Productos importados del medio litoral o urbano}

\subsection{El turismo residencial}

El turismo de segunda residencia cuenta con una larga tradición y una fuerte implantación en España. En este sentido, el crecimiento del parque de viviendas en España ha sido superior al de las unidades familiares, debido a la importancia de las viviendas secundarias y desocupadas (Lardiés, 2003). El 20,7\% de los hogares dispone de al menos una segunda vivienda. España, según datos de la UE de 2001, estuvo a la cabeza con un 32,2\% de su parque inmobiliario dedicado a esta tipología, seguido por Portugal (26,9\%), Grecia (22,7\%) e Italia (17,7\%) (Cebrián y García González, 2009). En la actualidad, el estallido de la burbuja inmobiliaria y la crisis del sistema financiero han provocado un fuerte estancamiento en los desarrollos urbanísticos, realidad que está afectando profundamente a la productividad y al empleo de todos estos países mediterráneos.

El protagonista de esta modalidad turística suele ser una unidad familiar con edad media elevada y un cierto poder adquisitivo. Este tipo de turismo suele presentar un gasto por persona menor que en el turismo tradicional, aunque su lugar de compra es el mismo que el del residente habitual (Torres, 2003). La implantación ha sido masiva en zonas costeras y periurbanas, pero también está muy presente en buena parte de los municipios y pueblos del interior peninsular. Ello está asociado al turismo de retorno (Cebrián y García González, 2009).

El turismo residencial se asocia generalmente a la adquisición de una vivienda por parte de extranjeros para ser usada en estancias prolongadas. A este respecto, se pueden diferenciar tres perfiles de turistas residentes: los ciudadanos que viven en España la mayor parte del tiempo y que regresan en verano a sus países; los visitantes estacionales, fundamentalmente en periodos vacacionales, y, por último, los visitantes con periodos de estancia diversos e irregulares. Lo más habitual es que este colectivo de residentes sea de edad avanzada y se localice en comarcas litorales. Sin embargo, la masificación de estos espacios ha generado nuevas dinámicas en las que están apareciendo «urbanizaciones» turístico-residenciales en espacios interiores, sobre todo en aquellos municipios que presentan mejores comunicaciones con el litoral. Esta nueva realidad, actualmente ralentizada por la crisis financiera e inmobiliaria, se estaba desarrollando gracias a las facilidades que otorgaban ciertos ayuntamientos para la recalificación de suelo rústico (permisividad urbanística), el menor coste del suelo (los residentes preferían un chalet en el interior a un apartamento en el litoral ) y las mejores condiciones ambientales y paisajísticas del entorno (menor masificación y mayor calidad de vida).

\subsection{El turismo de golf}

Habitualmente, este producto turístico aparece como valor añadido a complejos urbanísticos litorales. Así, aunque todavía no son muy frecuentes los 
campos de golf en el interior, sí lo son los proyectos presentados a las administraciones públicas que están a la espera de recalificaciones, aceptación social, superación de la crisis financiera e inmobiliaria o la llegada de nuevos aportes hídricos, como, por ejemplo, en la Comunitat Valenciana

El turista que consume este producto presenta un nivel de renta medio-alto, generalmente es varón y de edad media-alta. Fundamentalmente, se trata de turistas internacionales que proceden sobre todo del Reino Unido y Alemania. La motivación principal de estos turistas es la práctica del golf o la asistencia a competiciones profesionales de golf. La práctica de este deporte constituye la razón principal del viaje, pero no es la única motivación, ya que también se busca gastronomía, ocio y actividades relacionadas con la salud y la belleza. El turista de golf suele organizar su viaje de forma individual utilizando vuelos regulares. La estancia en el destino suele ser prolongada (más de una semana) y la mayor parte del tiempo se dedica a la práctica del golf en diferentes campos próximos (al menos tres). El nivel de gasto es elevado y el alojamiento se suele realizar en hoteles de categoría superior, aunque también son muy frecuentes las estancias en apartamentos y viviendas propias.

\subsection{El turismo de negocios}

Este producto se vincula a la práctica de actividades profesionales y empresariales (ferias, contactos de trabajo, relaciones comerciales, etc.). En los municipios de interior, solamente aparece en áreas muy concretas: ciudades intermedias (capitales comarcales), zonas industriales y nudos comerciales con buenos accesos por carretera.

En el turismo de negocios, las estancias suelen ser cortas, aunque todo depende del volumen de actividad lucrativa que genere cada área interior. Sin embargo, el nivel de gasto suele ser elevado, siempre por encima del turista convencional. Asimismo, las reuniones de trabajo suelen aumentar significativamente el gasto en restauración, sobre todo en aquellos restaurantes más exclusivos o típicos del lugar.

\subsection{El turismo de congresos}

Este producto turístico agrupa a los asistentes a congresos, convenciones, jornadas, seminarios y simposios. A pesar de que, en la actualidad, la mayoría de los congresos se llevan a cabo en las capitales provinciales y las grandes ciudades del litoral, son varias las ciudades intermedias del interior que están interesadas en poner en funcionamiento este tipo de producto turístico, aunque si bien a menor escala.

El cliente de congresos y reuniones se caracteriza por un nivel económico y formativo elevado. Aunque la asistencia a los propios congresos y reuniones es la motivación principal, en la elección de un destino de congresos cada vez cobra más importancia la gama de actividades externas al mismo congreso que se ponen a disposición del congresista y de sus posibles acompañantes (visitas 
turísticas, gastronomía típica, actividades culturales, golf, ocio nocturno, compras, salud y belleza, etc.).

La estancia media suele ser de entre dos y cuatro días, dependiendo de la entidad del congreso y el grado de movilidad espacial de las sesiones. Por su parte, el nivel de gasto es elevado, sobre todo en temas de compras y alimentación. La tipología de alojamiento más común es el hotel de categoría superior (normalmente hoteles de cuatro estrellas).

\section{Discusión y conclusiones}

Tras comprobar y analizar conceptualmente el amplio abanico de posibilidades turísticas que presentan los espacios de interior, llega la hora de preguntarse si toda esta amalgama productiva podrá ser capaz de interactuar de forma positiva o si, por el contrario, el interior llegará a convertirse en un "cajón de sastre», donde las diferentes modalidades turístico-recreativas entren en conflictos de intereses a la hora de compartir el espacio y satisfacer las necesidades particulares de los diferentes segmentos de demanda.

La reflexión teórica llevada a cabo en este artículo permite esgrimir los argumentos necesarios para la definición y la composición de una matriz de compatibilidad productiva, que pretende esclarecer las interacciones y el grado de compatibilidad integral de las diferentes manifestaciones turísticas presentes en los espacios interiores (tabla 3).

La variable "grado de compatibilidad» pone de relieve el tipo de relaciones existentes (positivas o negativas) entre los principales productos turísticos presentes en los espacios interiores, que han sido objeto de análisis teórico en los apartados de este artículo, con aquellos factores que se consideran cruciales para el correcto desarrollo del turismo de interior (medio ambiente, otros sectores de actividad económica, sociedad local, diferentes segmentos de demanda turística, posibilidad de desarrollar dinámicas de complementariedad territorial y productiva, capacidad innovadora y competitividad). Por otro lado, la matriz pone también de manifiesto el grado de interacción de dichos factores con los diferentes productos turísticos.

La marca de un punto en la matriz determina que un producto turístico concreto es compatible e interactúa positivamente frente a un factor determinado. Sin embargo, lo más interesante es conocer, a través del sumatorio de dichos puntos, qué productos turísticos pueden encajar mejor en los espacios de interior y que factores interactúan de un modo más positivo o se ven menos afectados por la implantación y el desarrollo de la actividad turística.

A la vista de los resultados que presenta la matriz de compatibilidad productiva, el turismo cultural y el enoturismo permiten un mayor grado de ajuste integral, seguidos del turismo relacional, el turismo de salud y belleza y el turismo activo. Sin embargo, la implantación y el desarrollo de otras modalidades, como el turismo de negocios, de congresos, de golf y residencial, resultan más conflictivas en espacios interiores. Asimismo, en líneas generales y en función de los diferentes aspectos valorados, la actividad turística en espacios interiores 
Tabla 3. Matriz sobre compatibilidad productiva en espacios turísticos de interior

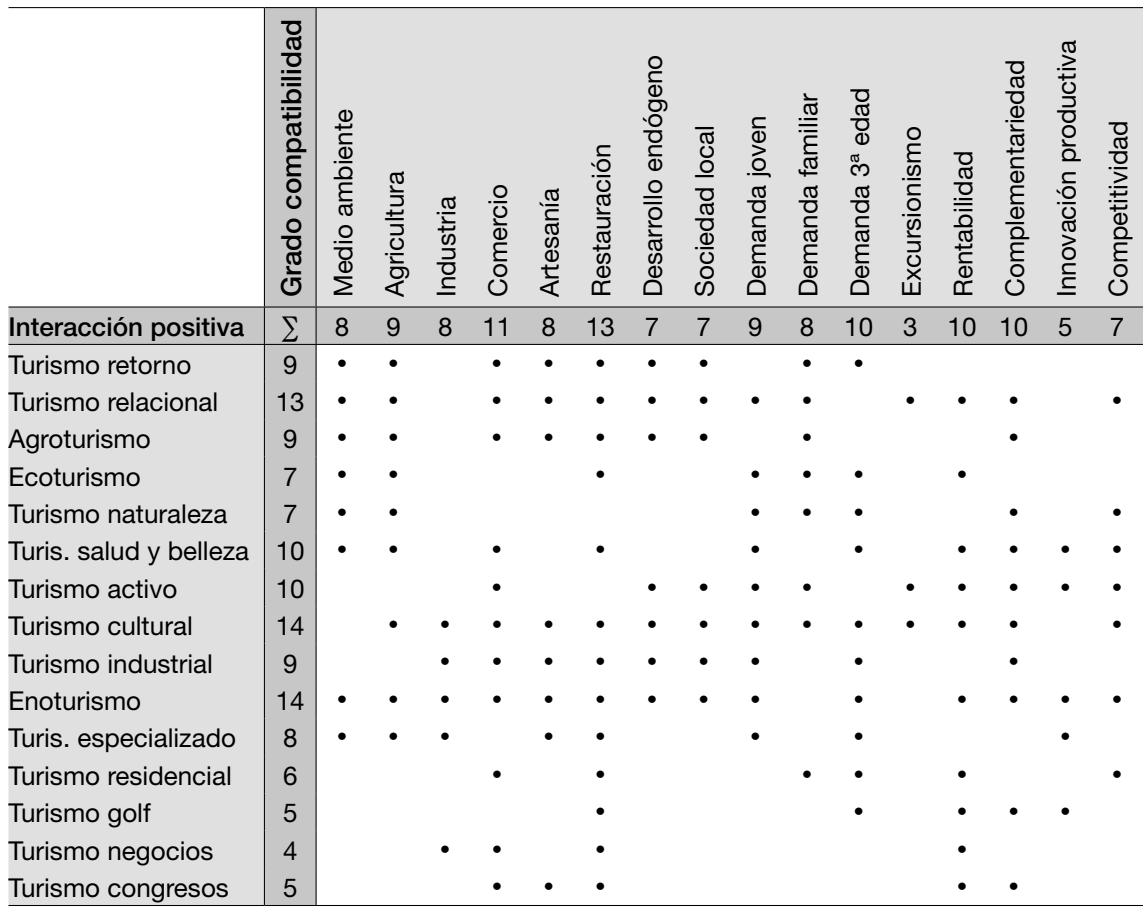

Fuente: elaboración propia.

genera una mayor interacción positiva sobre la restauración y el comercio, la demanda joven y senior y las posibilidades de desarrollar dinámicas de complementariedad, tanto territorial como productiva.

En la actualidad, los espacios turísticos de interior tienen ante sí un importante reto que deberán afrontar a través de una correcta planificación estratégica. Tan solo de este modo se podrán encontrar soluciones de compatibilidad de usos y funciones territoriales, sociales, económicas y ambientales, transformando las amenazas que trae consigo el libre albedrío en oportunidades simbióticas, complementarias y generadoras de sinergias.

\section{Bibliografía}

Antón, S.; López, R. (1996). "Turismo rural, desarrollo local y preservación del ambiente: Elementos para un desarrollo sostenible del turismo en la zona de montaña Prades-Montsant, Cataluña». Ería, 41, 227-238.

Blangy, S. (1995). "Écotourisme, tourisme durable et tourisme rural». Les Cahiers Espaces, 42.

BlázQuez, M. (2005). "El territorialismo y el ecologismo frente al turismo». Scripta Nova: Revista Electrónica de Geografía y Ciencias Sociales. Barcelona: Universidad de Barcelona, 1 de agosto, vol. IX, n. ${ }^{o} 194$ (24). 
Boo, E. (1993). «Turismo y Medio Ambiente». Editur, 1715.

Buckley, R. (1994). "A framework for Ecotourism». Annals of Tourism Research, 21, (3), 661.

Butler, R. (1992). «Alternative Tourism: The thin edge of the wedge». En: Smith, V.L.; Eadington, W.R. (eds.). Tourism Alternatives: Potentials and Problems in the Development of Tourism. Filadelfia: University of Pennsylvania Press.

Calabuig, L. y Ministral, M. (1994). Manual de Geografía Turística de España. Madrid: Síntesis.

Calatrava, J. (2001). "Agricultura y Turismo en el medio rural: Aspectos conceptuales y algunas reflexiones sobre su interacción». En: Buendía, J.D. y Colino, J. (eds.). Turismo y medio ambiente. Madrid: Civitas, 133-158.

Cànoves, G. y Villarino, M. (2000). «Turismo en espacio rural en España: Actrices e imaginario colectivo". Documents d'Anàlisi Geográfica, 37, 51-77.

Casillas, J.C. (1995). "El turismo alternativo como sistema integrado: Consideraciones sobre el caso andaluz». Estudios Turisticos, 125, 53-75.

Ceballos, I. (1993). Geografia turística de España. Madrid: Centro de Estudios Ramón Areces.

Cebrián, F. y García González, J.A. (2009). «Dimensiones territoriales del turismo rural en Castilla-La Mancha». Serie Geográfica, 15, 79-91.

Cors Iglesias, M. (2007). «El agroturismo en la Cataluña interior: El caso de la Sierra de Castelltallat». En: Antón, S. y González, F. (coords.). A propósito del turismo: La construcción social del espacio turístico. Barcelona: UOC, 225-232.

Darst, P. y Armstrong, G. (1980). Outdoor Adventure Activities for School and Recreation Programs. Minneapolis: Burgess Pub., 307 p.

Donaire, J.A. y Gordi, J. (2003). «Bosque y Turismo». Boletín de la Asociación de Geógrafos Españoles., 35, 207-221.

Ewert, A. (1987). «Recreation in the Ourdoor Setting; A Focus on Adventure-based Recreational Experiencies». Leisure Information Quaterly, 14 (1), 5-7

- (1989). Outdoor Adventure Pursuits: Foundation, Models and Theories. Columbus: Publishing Horizons, $234 \mathrm{p}$.

Ewert, A. y Hollenhorst, S. (1989). «Testing the adventure model: Empirical Support for a model of risk Recreation participation». Journal of Leisure Research, 21 (2), 124-139.

Fennell, D.A. (1999). Ecotourism: An Introduction. Nueva York: Routledge, 315 p.

Font, X. y Tribe, J. (eds.) (2000). Forest Tourism and Recreation: Cases Studies in Environnmental Mangement. Wallingford: CAB International.

García Henche, B. (2003). Estrategias de Marketing del Turismo Rural en Guadalajara. Servicio de Publicaciones de la Universidad de Alcalá.

García Saura, P.J. (2010). "Turismo activo y medio ambiente: una implicación necesaria. Aspectos jurídicos». Cuadernos de Turismo, 26, 153-176.

Generalitat Valenciana (2005). El turismo rural en la Comunitat Valenciana. Valencia: Conselleria de Turisme.

Getz, D.; Brown, G. (2006). «Critical success factors for wine tourism regions: A demand analysis». Tourism Management, 27 (1), 146-158.

Gómez-Limón, F.J.; De Lucio, J.V. (1995). «Recreational activities and loss of diversity in grasslands in Alta Manzanares Natural Park, Spain». Biological Conservation, 74 (2), 99-105.

Hall, C.M. (1989). «Special Interest Travel: A Prime Force in the Expansion of Tourism?». En: Welch, R. (ed.). Geography in Action. Dunedin: University of Otago, 81-89. 
Hermanin, L.; Zingari, P.C. y Zoanetti, R. (1988). «La funzione turístico-ricreativa nell'assestamento dei boschi trentini». Annali - Academia Italiana di Scienze Forestali, 37, 401-430.

Honey, M. (1999). Ecotourism and Sustainable Development: Who Owns Paradise? Washington D.C.: Island Press, 405 p.

Iso-Ahola, S. (1980). The Social Psychology of Leisure and Tourism. Dubuque: William. C. Brown Co.

Ivars, J.A. (1996). Análisis del potencial desarrollo turístico integrado de la Montaña de Alicante. Memoria de licenciatura. Departamento de Análisis Geográfico Regional. Universidad de Alicante

- (2000). «Turismo y espacios rurales: conceptos, filosofías y realidades». Investigaciones Geográficas, 23, 59-88.

LARDIÉs, R. (2003). «Turismo residencial e inmigración de jubilados extranjeros en España. Motivaciones para el desplazamiento». En: Actas del VII Coloquio de Turismo, 297-308.

Llurdés CoIt, J. (1995). El Turismo de Patrimonio Industrial y Minero: Una experiencia de turismo interior explotada en el Estado español. Departamento de Geografía. Universidad Autónoma de Barcelona.

López Colás, J. (2003). La residencia secundaria en España: Estudio territorial de su uso y tenencia. Tesis doctoral. Universidad Autónoma de Barcelona.

López Monné, R. (1998). «Evolució i canvi de model del senderisme a Catalunya: De l'associacionisme a l'activitat turística". Documents d'Anàlisi Geográfica, 33, 203-214.

Manero, F. (1997). "Experiencias de turismo interior: logros y fracasos desde la perspectiva del desarrollo local». En: VAlenzuela, M. (coord.). Los turismos de interior: El retorno de la tradición viajera. Madrid: Universidad Autónoma de Madrid.

Manning, R. (1986). Studies in outdoor recreation: Search and research for satisfaction. Corvallis: Oregon State University Press, 166 p.

Meier, E. (1978). «Is the Risk Worth Taking?». Leisure Today, 49 (4), 7-9.

Merg, M. (1999). Defining Ecotourism [en línea]. <http://www.untamedpath.com/ Ecotourism/defining.html> [Consulta: 28 abril 2009].

Pardo, C.J. (2010). «El patrimonio industrial en España: Análisis turístico y significado territorial de algunos proyectos de recuperación». Boletín de la Asociación de Geógrafos Españoles, 53, 239-264.

Paz, C. y Visvequi, R. (2001). Turismo Industrial y Patrimonio Cultural en Olavarría: El pasado de la industria minera como potencial turístico. Proyecto de Turismo Industrial. Grupo de Investigación en Antropología y Arqueología Industrial (GIAAI). NURES. Facultad de Ciencias Sociales de Olavarría. Universidad Nacional del Centro de la Provincia de Buenos Aires.

Pearce, D.G. (1992). "Alternative Tourism: concepts, classifications, and questions». En: smith, V.L. y Eadington, W.R. (eds.). Tourism Alternatives: Potentials and Problems in the Development of Tourism. Filadelfia: University of Pennsylvania Press.

Progen, J. (1979). «Man, Nature, and Sport». En: Gerber, E. y Nillian, M. (eds.). Sports and the Body: A Philosophical Symposium. Filadelfia: Lea Febiger, 237-242.

Pulido, J.I. y CÁrdenas, P.J. (2011). «El turismo rural en España: Orientaciones estratégicas para una tipología aún en desarrollo». Boletín de la Asociación de Geógrafos Españoles, 56, 155-176.

Reyna, S. (coord.) (1992). El turismo rural en el desarrollo local. Actas del Seminario [celebrado en] Laredo, 22-26 de julio de 1991. Madrid: Ministerio de Agricultura, Pesca y Alimentación. 
Rodríguez, L.; López, T.; Cañizares, S.M. y Jiménez, M. (2010). «Turismo del vino en el marco de Jerez: Un análisis desde la perspectiva de la oferta». Cuadernos de Turismo, 26, 217-234.

Sancho, J. y Vera, J.F. (coords.) (2008). Atlas Nacional de España: Turismo en Espacios Rurales y Naturales de España. Madrid: Instituto Geográfico Nacional. Centro Nacional de Información Geográfica.

Santana, A. (2006). Antropología y turismo. ¿Nuevas hordas, viejas culturas? Barcelona: Ariel, 220 p.

Sayadi, S. y Calatrava, J. (1997). El potencial agroturistico: Análisis preliminar de un sondeo en la Alpujarra Alta Oriental granadina. Documento del curso de verano Estrategias Turísticas y Desarrollo Rural: Oportunidades y Limitaciones. Centro Mediterráneo de Granada.

SAYADI, S. (1998). Análisis de la potencialidad de los sistemas agrarios en el desarrollo local de zonas rurales: el caso de la alta Alpujarra. Tesis doctoral. Instituto de Sociología y Estudios Campesinos. Universidad de Córdoba.

Soyez, D.A. (1993). "Industrietourismus neue Chance für alte Industrieregionen?». En: Becker, Ch. y Steinecke, A. Megatrend Kultur?: Chacen und Risken der touristischen Vermarktung des kulturellen Erbes. Europäisches Wissenschaftsforum auf der Internationalen Tourismus-Börse Berlin 93, ETI, Europäiches Tourismus Institut GMBH an der Universität Trier, 42-56.

Sung, H.H.; Morrison, A.M. y O'Leary, J. T. (1996). «Definition of adventure travel: Conceptual framework for empirical application from the providers' perspective». Asia Pacific Journal of Tourism Research, 1 (2), 47-67.

Susmel, L. (1968). "La terza dimensione della foresta». Annali-Academia Italiana di Scienze Forestali, 32.

Torres, E. (2003). «El turismo residenciado y sus efectos en los destinos turísticos». Estudios Turísticos, 155-156, 45-70.

TuÑón, F.J. (1992). «El turisme a l'espai rural: Una experiència pràctica que explica un model teòric». Simposi Internacional de Turisme a Catalunya. Barcelona: ESADE.

Valenzuela, M. (1984). "El uso recreativo de los espacios naturales de calidad (Una reflexión sobre el caso español)». Estudios Turísticos, 82, 3-15.

- (1997). Los turismos de interior: El retorno de la tradición viajera. Madrid: Ediciones de la Universidad Autónoma de Madrid, 752 p.

Velasco, M. (2009). «Gestión turística del patrimonio cultural: Enfoques para un desarrollo sostenible del turismo cultural». Cuadernos de Turismo, 23, 237-253.

Velluti Zati, S. (1988). Tourisme et loisirs en milieu rural. Bruselas: Conseil de l'Europe.

Vera, J.F.; López, F.; Marchena, M.J. y Antón, S. (2011). Análisis territorial del turismo y planificación de destinos turisticos. Valencia: Tirant lo Blanch.

Weaver, D.B. (1991). "Alternative to Mass Tourism in Dominica». Annals of Tourism Research, 18, 414-432.

Yepes, V. (1995). "Turismo sostenible en el interior de la Comunidad Valenciana: posibilidad de un desarrollo turístico complementario al del "sol y playa"». Papers de Turisme, 75-87. Valencia: ITVA (Institut Turístic Valencià).

Yerkes, R. (1985). "High Adventure Recreation in Organized Camping». Trends, $22(3), 10-11$. 